\title{
Strategic delegation in oligopoly : the market share case
}

Citation for published version (APA):

Jansen, T. L., van Lier, A., \& van Witteloostuijn, A. (2004). Strategic delegation in oligopoly : the market share case. METEOR, Maastricht University School of Business and Economics. METEOR Research Memorandum No. 049 https://doi.org/10.26481/umamet.2004049

Document status and date:

Published: 01/01/2004

DOI:

10.26481/umamet.2004049

Document Version:

Publisher's PDF, also known as Version of record

\section{Please check the document version of this publication:}

- A submitted manuscript is the version of the article upon submission and before peer-review. There can be important differences between the submitted version and the official published version of record.

People interested in the research are advised to contact the author for the final version of the publication, or visit the DOI to the publisher's website.

- The final author version and the galley proof are versions of the publication after peer review.

- The final published version features the final layout of the paper including the volume, issue and page numbers.

Link to publication

\footnotetext{
General rights rights.

- You may freely distribute the URL identifying the publication in the public portal. please follow below link for the End User Agreement:

www.umlib.nl/taverne-license

Take down policy

If you believe that this document breaches copyright please contact us at:

repository@maastrichtuniversity.nl

providing details and we will investigate your claim.
}

Copyright and moral rights for the publications made accessible in the public portal are retained by the authors and/or other copyright owners and it is a condition of accessing publications that users recognise and abide by the legal requirements associated with these

- Users may download and print one copy of any publication from the public portal for the purpose of private study or research.

- You may not further distribute the material or use it for any profit-making activity or commercial gain

If the publication is distributed under the terms of Article $25 \mathrm{fa}$ of the Dutch Copyright Act, indicated by the "Taverne" license above, 


\title{
STRATEGIC DELEGATION IN OLIGOPOLY:
}

\section{THE MARKET SHARE CASE}

\author{
Thijs Jansen ${ }^{\mathrm{a}}$, Arie van Lier ${ }^{\mathrm{b}, *}$ and Arjen van Witteloostuijn ${ }^{\mathrm{b}}$ \\ ${ }^{\mathrm{a}}$ Department of Quantitative Economics, University of Maastricht, Maastricht, The Netherlands \\ ${ }^{\mathrm{b}}$ Department of International Economics and Business, University of Groningen, Groningen, The Netherlands
}

\begin{abstract}
In this paper, we consider a two-stage (sequential) game as introduced by Vickers (1985), Fershtman (1985), Fershtman and Judd (1987) and Sklivas (1987). This game models the situation where the owners of competing firms manipulate their managers' incentive contracts for strategic reasons. Instead of the sales volume as part of these contracts, we introduce market share, besides profit, as a natural part of managers' incentives. Then we compare the results with those obtained for combinations of profits and sales volume, as well as for the classical Cournot model. Concerning an $n$-firm oligopoly, and compared to the sales-delegation case, it appears that owners put more emphasis on managerial profit-maximizing behavior, indicated by smaller weights attributed to market share in managerial incentive contracts. Social welfare corresponding to the market share-delegation case almost equals welfare associated with the sales-delegation case. However, its components differ. The case of market share-delegation leads to a higher profitability of incumbent rivals and to a lower consumer surplus, in comparison to the sales-delegation case. One may state that the owner's strategic use of market share as a managerial incentive leads to a (partial) shift of benefits from consumers to producers.
\end{abstract}

JEL classification: D21; D43; C72; L13

Keywords: Strategic delegation; Oligopoly; Managerial incentives

* Corresponding author: e-mail address: a.j.van.lier@eco.rug.nl.

Tel.: +31-50-3633661; fax: +31-50-3637337. 


\section{Introduction}

Traditional economic theories of direct competition use the highly simplified assumption that the single aim of rivaling firms is profit maximization. However, in large companies, ownership and management are separated, and managerial decision processes are rather complex. Already in the 1950s, Baumol (1958) realized that managers may be driven by other motives than pure profit-maximization, and he suggested a sales-maximization model as a more realistic alternative. Managerial economics, which became a new sprout emerging from the tree of economics, focused on this very issue of managerial motives. By directly estimating managers' objectives, two early representatives of managerial economics, namely Hall (1967) and Lackman and Craycroft (1974), supported the sales-maximization hypothesis empirically. In a similar vein, market share may provide a crucial motive for managers. Peck (1988) reports the empirical findings of a survey in corporate objectives among 1,000 American and 1,031 Japanese top managers. Increasing market share ranks third in the American and second in the Japanese sub-sample, whereas return on investment is first among American and third among Japanese top managers. Furthermore, the role of nonprofit incentives is evident from empirical studies in the agency tradition, such as those of Jensen and Murphy (1990) and Lambert, Larcker and Weigelt (1991) into managerial compensation practices. These studies reveal that executive bonuses and salaries are associated with both firm size and profit level, with the size correlations being the stronger of the two. Clearly, managerial compensation schemes point at the crucial fact that managers' behavior can be influenced or manipulated by owners in a principal-agent context.

The strategic use of managers' incentive contracts in direct competition has been introduced in the 1980s by the path-breaking papers of Vickers (1985), Fershtman (1985), Fershtman and Judd (1987) and Sklivas (1987). These contributions offer a game-theoretic explanation for managers' nonprofit-maximizing behavior. These studies consider the separation of owners (principals) and managers (agents), and examine a two-stage sequential game, where in the first stage (the 'contract stage') the owner writes his manager's incentive contract, which is publicly announced, before competition evolves in the second stage. Concerning all these principal-agent models, manager's contract consists of a (linear) combination of profits and production volume (we note that Fershtman and Judd (1987) and Sklivas (1987) use a combination of profits and revenues, but this combination can be rewritten as a combination of profits and output volume). In the consecutive stage (the 'market stage'), firms' managers decide on market supply, using the utility function directed by the contract, because their compensation depends on it. The two-stage game is solved by the usual method of backward induction: knowing the Nash equilibrium at the market stage, owners can choose the weights attributed to output volume in the incentive contract such that, given the rival's contract, their profit is maximized. This strategic manipulation by all owners of the incumbent firms leads to a so-called subgame-perfect equilibrium (SPE), concerning contracts' weights attributed to output volumes.

These four papers led to fruitful consecutive studies in which researchers adopted the basic concept of these delegation games in their examinations. For instance, Szymanski (1994) deals with managerial cost control in a bargaining process with unions, Basu (1995) introduces an extra stage in the sequential game where the owner decides to hire a manager or not and provides an interesting game-theoretic explanation for Stackelberg leadership, and Ziss (2001) and González-Maestre and López-Cuñat (2001) examine the implications of 
strategic delegation for market structure by analyzing the conditions for endogenous or exogenous mergers. So one could say that the study of delegation games is still enriched with several expansions and refinements. However, all these authors assume that managers' incentive contracts consist of a combination of profits and (weighted) production levels. In the current paper, we offer a twofold contribution. First, we explore another delegation game, with market share rather than sales delegation. Second, we generalize the mathematical methodology used to analyze delegation games. Before we introduce our market share version of a delegation game, we first discuss both contributions in greater detail.

\section{Market share as part of manager's contract}

This paper deals with the introduction of a different nonprofit-maximizing objective of firms' managers in the Cournot oligopoly case, namely market share. We adopt the concept of a two-stage sequential game, where at the contract stage firm's owner writes his manager's incentive contract, which consists of a linear combination of profits and market share. Again, the owner's objective is to manipulate his manager's contract such that, given the rival's contract, his profit is maximized. This strategic delegation sounds very familiar, so first we argue that market share, as part of the contract, may provide an interesting modification (and hopefully a further enrichment) of the models of Vickers (1985), Fershtman (1985), Fershtman and Judd (1987), Sklivas (1987), and the delegation games that followed upon this set of pioneering studies. A first argument comes from an empirical angle. The early study of Peck (1988) already pointed at the importance of managerial preference for market share, and therefore justifies an examination of the implications of market share in manager's incentive contract. Since then, much anecdotal evidence about the importance of market share motives emerged in the business press and management literature. A classic example is Jack Welch's General Electric, which publicly announced that its key objective is to be number one in all the markets in which it operates. Another example is the recent and still ongoing price war between the large supermarkets in the Netherlands, which was triggered by a decrease of the market share of Albert Heijn in the aftermath of the Ahold accounting scandal and a disproportionate bonus deal with the new Chief Executive Officer the former IKEA top manager - Anders Moberg. The market shares of all involved rivals received (and still receive) much attention of the media, which underlines market share as a status motive in direct competition. A final example relates to media industries, where market share in terms of listeners (radio stations), readers (newspaper dailies) and viewers (TV channels) are the key to success.

The fact that owners - and their managers - attach significant value to their market share in direct competition, and therefore consider it to be an important indicator of managerial performance, seems to be a 'natural' aspect of human nature, as much evidence exists that many economic agents are interested in their relative rather than their absolute performance. In modelling consumer behavior, for instance, status motives have been used to describe the additional purpose of consuming a so-called positional good. For example, Rauscher (1992) analyzes a 'status-game' between two neighbors. In a similar vein, experimental economics has produced support for this assumption of relative utility maximization - for example, in the context of so-called ultimatum games (Güth, Kliemt and Ockenfels (2003)). One could say that sales is an absolute measure, because it does not involve rival's market supply explicitly. However, market share, taking into account competitor's output performance, provides a relative indicator and can be seen as a status motive in rivalry. In the finance literature, for example, the status-like hubris motive is found to be a 
main driver behind M\&As (Fernández, Baixauli and Samuel (2003)). The fact that a firm is likely to keep an eye on its rival's performance speaks for the introduction of this relative indicator in a delegation game. We examine the case of Cournot-quantity competition and compare our analytic results, such as the (equilibrium) weight attributed to market share in a manager's contract, the output corresponding with the incentive equilibrium at the second stage of the game, firms' equilibrium profits and social welfare, with the results of the sales-delegation games in the tradition of Vickers (1985), Fershtman (1985), Fershtman and Judd (1987) and Sklivas (1987). Besides the consideration of the economic implications of market share as part of managers' incentive contracts, we will first reflect on the mathematical method to solve this two-stage game.

\section{Mathematical methodology}

Despite the fact that the method to solve a two-stage sequential game is straightforward and rests on backward induction, the introduction of market share in the contracts strongly complicates the mathematical analysis in comparison with the sales-delegation case. The case of market share introduces a system of analytically non-solvable equations at the market stage of the game, so we do not use our method just for fun, but are forced to use more complicated analysis. The advantage of our method is its applicability to general incentives in the contracts, because explicit expressions of profits and outputs concerning the Nash equilibrium at the second stage of the game are not needed. Our method makes use of essential properties of equilibrium profits and outputs, and also emphasizes the crucial requirements for the existence of a unique Nash equilibrium at the second stage and a unique subgame-perfect equilibrium at the game's contract stage. To clarify the hurdles we have to take, we briefly run through the methodology of the well-known sales-delegation case. There the Cournot-Nash equilibrium at the second stage of the game is clearly unique and, by solving a system of linear equations, market supplies can be explicitly expressed as functions of the weights of sales in managers' incentive contracts. As a consequence, competitors' profits can be expressed relatively simply as a function of these weights so that the application of the principle of backward induction - i.e., maximization of each profit function, given rivals' weights in their contracts - is rather easy.

However, if market share is part of managers' contracts, managers' output decisions naturally depend on their utility functions, consisting of a linear combination of profits and market share. Instead of linear best-response curves in the sales-delegation case, we now have to deal with non-linear reaction curves at the game's market stage. The mathematical expressions of such reaction functions are rather complicated, which can be determined by solving a third-degree equation, using Cardan's method (see van Lier (2003)). Clearly, the uniqueness of the Cournot-Nash equilibrium in the duopoly case (roughly speaking, the intersection point of two reaction curves) may not be taken for granted, but has to be proved. Note that the existence of more equilibria, at the second stage of the game, would strongly complicate the analysis of the contract stage. We observe that existing game-theoretical uniqueness theorems are not applicable in our case, but fortunately we are able to provide a uniqueness proof, using some essential properties of managers' bestresponse curves. However, expressing market supplies as explicit formulas, concerning the duopoly case, is impossible, because it involves the solving of a system of two third-degree equations with different values for the weights $w_{1}$ and $w_{2}$ in it (here $w_{i}$ denotes the weight attributed to market share in manager $i$ 's contract). Therefore, we have to resort to the Implicit Function Theorem to deduce the essential properties of the 
equilibrium quantities - in the duopoly case: $q_{1}\left(w_{1}, w_{2}\right)$ and $q_{2}\left(w_{1}, w_{2}\right)$, where $q_{i}$ is the quantity produced by firm $i$ - at the market stage of the game. We also lack explicit mathematical expressions for both firms' profit levels, corresponding to two (differing) managerial contracts. Notwithstanding this complication, we show that the first-order conditions $\frac{\partial \pi_{1}}{\partial w_{1}}=0$ and $\frac{\partial \pi_{2}}{\partial w_{2}}=0$ (here $\pi_{i}$ denotes firm $i$ 's profit) for the profit levels lead to two usable equations. To show that, given the contract of the rival's manager, there only exists one unique contract which maximizes one's own profits (the best response at the contract stage), again involves more mathematical refinements.

Naturally, we pay attention to the composition of the incentive contracts - i.e., the weights attributed to market share, resulting from strategic delegation. Furthermore, we reflect on the analytic outcomes of important economic indicators, such as market supply, profits of the incumbent rivals and social welfare. A comparison with the results of standard Cournot and the sales (revenue) cases of Vickers (1985), Fershtman (1985), Fershtman and Judd (1987) and Sklivas (1987), concerning Cournot-quantity competition, is obvious. Concerning this paper, we restrict our examinations to firms with equally efficient production technologies, reflected in equal (constant) marginal production $\operatorname{costs} c$. Then, the use of symmetry allows us to solve the weights $(w)$ in the incentive contracts and the resulting market supplies $(q)$ analytically, notwithstanding the non-linearity of the final set of equations in $w$ and $q$. We note that cost heterogeneity would involve numerical methods, although the methodology, presented in this paper, would still stand up. In section 2 the model's general framework is introduced, where we consider the market and contract stage of the game successively. Section 3 deals with a comparison with the sales-delegation case; first we concern a duopoly and then we briefly reflect on the $n$-firm Cournot case. Section 4 concludes the main text with an appraisal, whereas Appendices A,B,C and D contain all proofs in detail.

\section{The model}

We consider a duopoly situation with inverse demand given by

$$
p=\max \{0,1-Q\},
$$

where $p$ denotes price and $Q=q_{1}+q_{2}$ is total market supply; here $q_{i}$ is firm $i$ 's output. For both firms, the cost of producing 1 unit equals $c<1$. (Note that the model $p^{\prime}=\max \left\{0, a-b Q^{\prime}\right\}$ can be transformed into this model using $p=\frac{p^{\prime}}{a}, Q=\frac{b}{a} \cdot Q^{\prime}$.)

We assume that each firm has one owner and one manager playing a two-stage delegation game.

In the first stage, the owners simultaneously offer their managers a contract based on profits and some indicator measuring the manager's performance. In this paper, the indicator will be market share. Thus, for manager $i$ his compensation has the form $A_{i}+B_{i} U_{i}$, where $A_{i}$ represents his fixed salary, $B_{i} U_{i}$ equals a performance-related bonus, $B_{i}>0$ and

$$
U_{i}= \begin{cases}\pi_{i}+w_{i} \frac{q_{i}}{Q} & \text { if } \pi_{i} \geq 0 \\ 0 & \text { if } \pi_{i}<0\end{cases}
$$

with $w_{i} \geq 0$. After the weight (or contract) $w_{i}$ has been chosen, it is publicly announced.

In the second stage, the managers, knowing all the contracts, simultaneously choose their firms' output. 
In the first stage, the owner of firm $i$ will try to choose the weight $w_{i}$ in order to maximize his profits $\pi_{i}=q_{i}(1-c-Q)$, whereas his manager (knowing all the weights) chooses $q_{i}$ in order to maximize

$$
U_{i}=q_{i}(1-c-Q)+w_{i} \frac{q_{i}}{Q}
$$

In the next two subsections, in order to obtain a subgame-perfect equilibrium, the method of backward induction is employed to solve this delegation game. First, we determine for each pair of weights, $w_{1}$ and $w_{2}$, the unique equilibrium $\left(q_{1}\left(w_{1}, w_{2}\right), q_{2}\left(w_{1}, w_{2}\right)\right)$ of the corresponding 'market game'. Since the owners can anticipate these quantities, we subsequently determine the unique symmetric equilibrium of the 'contract game' where the payoff for owner $i$ is equal to his profits corresponding to the quantities $q_{1}\left(w_{1}, w_{2}\right)$ and $q_{2}\left(w_{1}, w_{2}\right)$.

\subsection{The market stage}

After the weights $w_{1}$ and $w_{2}$ are chosen in the first stage, the managers - knowing these weights - play the corresponding market game, where the $i$-th manager chooses a quantity $q_{i} \in[0,1]$ and where his utility is equal to

$$
U_{i}\left(q_{1}, q_{2}\right)= \begin{cases}q_{i}(1-c-Q)+w_{i} \frac{q_{i}}{Q} & \text { if } 0<Q \leq 1-c \\ 0 & \text { if } Q=0 \text { or } Q>1-c .\end{cases}
$$

Note that this utility function is discontinuous at 0 , which makes it impossible to apply the well-known results concerning the existence of equilibria. Instead we will establish the uniqueness of the (relevant) equilibrium by carefully considering the reaction curves of the players. Clearly, the market game has at least one equilibrium $\left(q_{1}, q_{2}\right)$ satisfying $Q>1-c$, which implies that profits are negative and that manager's utility equals zero. For obvious reasons, such equilibria will play no role in our analysis.

Now let $\left(q_{1}^{*}, q_{2}^{*}\right)$ be a Nash-Cournot equilibrium of the market game corresponding to a pair $\left(w_{1}, w_{2}\right)$. Since choosing the quantity $\frac{1}{2}(1-c)$ is the optimal reaction if the opponent produces nothing and choosing nothing is not optimal against $\frac{1}{2}(1-c), q_{1}^{*}>0$ and $q_{2}^{*}>0$. Furthermore, $q_{1}^{*}$ and $q_{2}^{*}$ satisfy the following system of equations:

$$
\left\{\begin{array}{l}
1-c-2 q_{1}-q_{2}+w_{1} \frac{q_{2}}{Q^{2}}=0 \\
1-c-q_{1}-2 q_{2}+w_{2} \frac{q_{1}}{Q^{2}}=0
\end{array}\right.
$$

In order to show that this system has a unique solution, in Appendix A, we prove that the second equation of this system corresponds, for fixed $w_{2}>0$, to a (reaction) curve $\mathcal{R}_{2}$ representing the graph of a differentiable, concave function, say $f$ (of $q_{1}$ ). Furthermore, we will describe the behavior of the graph of $f$ at the points $\mathrm{A}, \mathrm{B}$ and $\mathrm{C}$ (as represented in Figure 1). Note that the term reaction curve is somewhat misleading here. Only that part of the curve below the line $Q=1-c$ can be seen as a reaction curve. At first instance, however, the inequality $Q<1-c$ will be left out consideration. 


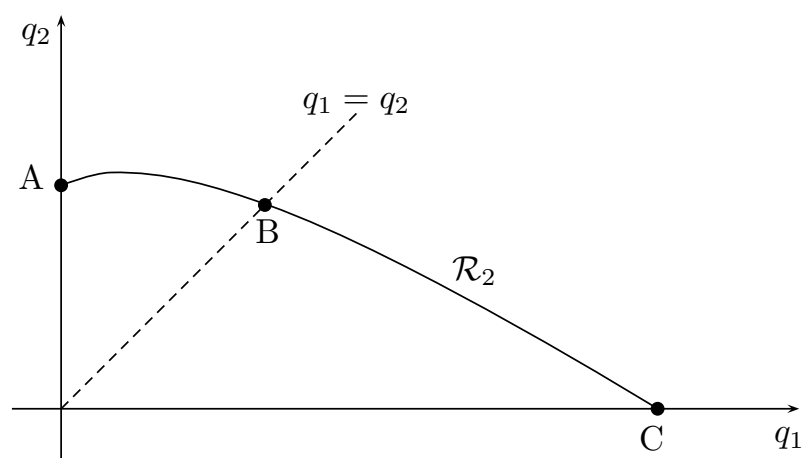

FIGURE 1 One of the reaction curves at the market stage

LEMMA 1 The second equation of system (1) corresponds, for fixed $w_{2}>0$, to a reaction curve representing the graph of a differentiable, concave function (of $\left.q_{1}\right)$.

Similarly, the first equation of system (1) corresponds, for fixed $w_{1}>0$, to a reaction curve $\mathcal{R}_{1}$ representing the graph of a differentiable, concave function, say $h$ (of $q_{2}$ ). However, a part of this reaction curve is also the graph of a differentiable concave function, say $g$ of $q_{1}$. In the following figure the graph of this function $g$ is represented (for the case $w_{1} \leq w_{2}$ ).

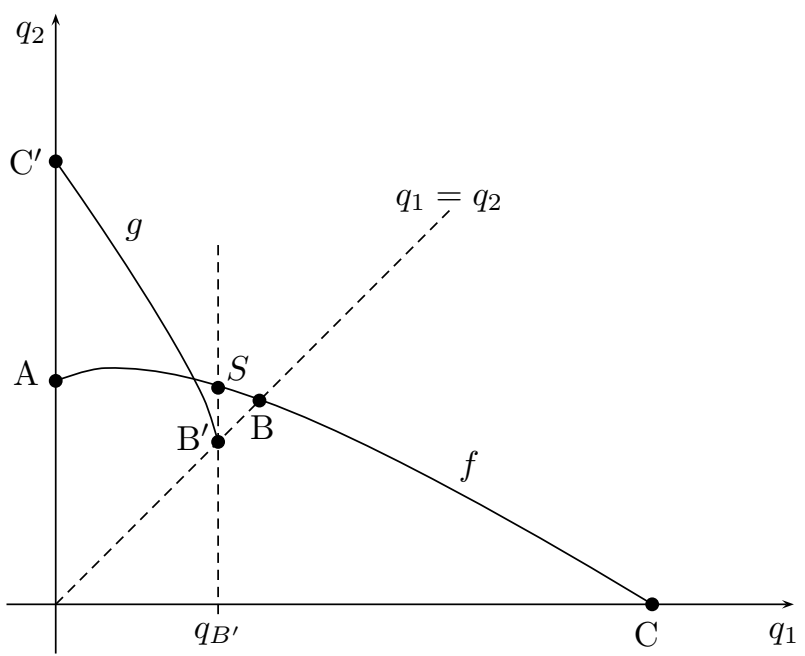

FIGURE 2 Unique intersection of both reaction curves

In order to prove this, we note that, according to Appendix A, for $q_{B^{\prime}}<q_{2}<q_{C^{\prime}}$,

$$
-\frac{1}{2}=h^{\prime}\left(q_{C^{\prime}}\right)<h^{\prime}\left(q_{2}\right)<h^{\prime}\left(q_{B^{\prime}}\right)=-\frac{1}{2+w_{1} / 4 q_{B^{\prime}}^{2}} .
$$

So on the interval $\left[q_{B^{\prime}}, q_{C^{\prime}}\right]$ the function $h$ is invertible. If $g=h^{-1}$, then for $0<q_{1}<q_{B^{\prime}}$

$$
-2=g^{\prime}(0)>g^{\prime}\left(q_{1}\right)>g^{\prime}\left(q_{B^{\prime}}\right)=-2-\frac{w_{1}}{4 q_{B^{\prime}}^{2}} .
$$

The foregoing will be used to prove the following result.

LEMMA 2 The system (1) has a unique solution.

PROOF We will prove that the graphs of the functions $f$ and $h$ intersect in precisely one point.

(a) We consider the function $d=g-f$ ( of $q_{1}$ ) on the interval $\left[0, q_{B^{\prime}}\right]$. For $0<q_{1}<q_{B^{\prime}}$,

$$
d^{\prime}\left(q_{1}\right)=g^{\prime}\left(q_{1}\right)-f^{\prime}\left(q_{1}\right)<-2-\left(-\frac{1}{2}\right)=-1 \frac{1}{2}<0 .
$$


Since $d(0)=g(0)-f(0)>0$ and $d\left(q_{B^{\prime}}\right)=g\left(q_{B^{\prime}}\right)-f\left(q_{B^{\prime}}\right)<0$, the graphs of the functions $g$ and $f$ intersect once.

(b) Next we restrict the analysis to the set of points $\left(q_{1}, q_{2}\right)$ satisfying $q_{2} \geq q_{1} \geq 0$ and $q_{1} \leq q_{B^{\prime}}$. On this set the graph of the function $h$ coincides with the graph of the function $g$. So, according to part (a), the graphs of the functions $h$ and $f$ intersect once on this set.

(c) Finally, we restrict the analysis to the set of points $\left(q_{1}, q_{2}\right)$ satisfying $0 \leq q_{2}<q_{1}$ or $q_{1}>q_{B^{\prime}}$. Now let $\ell$ be the tangent to the graph of the function $h$ at the point $\mathrm{B}^{\prime}$. The slope of the line $\ell$ is equal to $-2-\frac{w_{1}}{4 q_{B^{\prime}}^{2}}<-2$. Hence, this tangent is below the line between the points $\mathrm{C}$ and $\mathrm{S}$ (see Figure 2). Since the the function $f$ is concave, its graph is above this line. Since the function $h$ is concave, its graph is at the left-hand side of the tangent $\ell$. This proves that the graphs of the functions $h$ and $f$ do not intersect on the set under consideration.

Next we are going to investigate those solutions of system (1) implying total market supply less than $1-c$. Note that this condition was not taken into consideration until now. So for a given pair $\left(w_{1}, w_{2}\right)$ of contracts, let $\left(q_{1}^{*}, q_{2}^{*}\right)$ be the unique solution of system (1) satisfying $Q^{*}<1-c$. As is shown in the proof of Lemma 2 , it holds that

- $q_{1}^{*}>0$ and $q_{2}^{*}>0$

- given $q_{i}^{*}$, manager $j$ 's marginal utility is zero only at $q_{j}^{*}$, whereas the marginal utility switches sign at $q_{j}^{*}$ - that is, $q_{j}^{*}$ is the unique optimal reaction against $q_{i}^{*}$.

This proves that $\left(q_{1}^{*}, q_{2}^{*}\right)$ is the unique equilibrium of the relevant market game. Hence,

THEOREM 1 If for a pair of contracts the unique solution of system (1) implies a total market supply less than $1-c$, then this solution corresponds to the unique equilibrium of the market game.

\subsection{The contract stage}

In this phase of the game, each owner has to choose the weight in the manager's contract. Since for any relevant choice of weight combinations, the corresponding market game has a unique equilibrium, the owners - who want to maximize their profits - will anticipate this equilibrium. We will show that this situation, which can be modelled as a 'contract game', possesses a unique symmetric equilibrium - that is, an equilibrium where both owners choose the same weight, say $w^{*}$. Subsequently, the managers choose the same quantity, say $q^{*}$, in their market game.

More formally, owner $i$ chooses the weight $w_{i}$ in order to maximize his profits $\pi_{i}\left(w_{1}, w_{2}\right)$ given the quantities chosen in the market game. In order to describe these quantities, we note that given $w_{i}$, owner $j$ can always obtain a positive profit by choosing $w_{j}=0$. In that situation his manager's utility function coincides with the one in the classical Cournot game. Hence, his manager's reaction curve is the line segment between the points $\left(q_{1}, q_{2}\right)=(0,1-c)$ and $\left(\frac{1}{2}(1-c), 0\right)$. Since the equilibrium of the market game lies on this line, this implies that total market supply is strictly less than $1-c$ (note that $(0,1-c)$ is not an equilibrium). Since the owners can guarantee themselves a positive profit, we may assume that an equilibrium $\left(w_{1}, w_{2}\right)$ of the contract game implies a total market supply less than $1-c$. So according to Theorem 1 , the equilibrium $\left(q_{1}\left(w_{1}, w_{2}\right), q_{2}\left(w_{1}, w_{2}\right)\right)$ is the unique solution of the system (1), whereas

$$
\pi_{i}\left(w_{1}, w_{2}\right)=q_{i}\left(w_{1}, w_{2}\right)\left[(1-c)-q_{1}\left(w_{1}, w_{2}\right)-q_{2}\left(w_{1}, w_{2}\right)\right] .
$$


In Appendix B we show that the functions $q_{1}$ and $q_{2}$ possess continuous partial derivatives with respect to $w_{1}$ and $w_{2}$.

In order to find the optimal reaction of owner 1 against a fixed weight $w_{2}$ chosen by his opponent, we consider the first-order condition

$$
\frac{\partial \pi_{1}}{\partial w_{1}}=0 \Longleftrightarrow \frac{\partial q_{1}}{\partial w_{1}}\left[(1-c)-Q-q_{1}\right]-q_{1} \frac{\partial q_{2}}{\partial w_{1}}=0
$$

By implicitly differentiating (both sides of) the second equation of system (1) with respect to $w_{1}$, we obtain

$$
-\frac{\partial q_{1}}{\partial w_{1}}-2 \frac{\partial q_{2}}{\partial w_{1}}+w_{2} \frac{Q^{2} \frac{\partial q_{1}}{\partial w_{1}}-2 q_{1} Q\left(\frac{\partial q_{1}}{\partial w_{1}}+\frac{\partial q_{2}}{\partial w_{1}}\right)}{Q^{4}}=0
$$

or

$$
\frac{\partial q_{1}}{\partial w_{1}}\left[-1+w_{2} \frac{Q-2 q_{1}}{Q^{3}}\right]+\frac{\partial q_{2}}{\partial w_{1}}\left[-2-2 w_{2} \frac{q_{1}}{Q^{3}}\right]=0
$$

In combination with (2) this can be summarized as

$$
\left[\begin{array}{cc}
1-c-Q-q_{1} & -q_{1} \\
-1+w_{2} \frac{Q-2 q_{1}}{Q^{3}} & -2-2 w_{2} \frac{q_{1}}{Q^{3}}
\end{array}\right]\left[\begin{array}{c}
\frac{\partial q_{1}}{\partial w_{1}} \\
\frac{\partial q_{2}}{\partial w_{1}}
\end{array}\right]=\left[\begin{array}{l}
0 \\
0
\end{array}\right]
$$

Since $\frac{\partial q_{1}}{\partial w_{1}}>0$ (see Appendix B), the determinant of the coefficient matrix of this system must be zero. Using the problem's symmetry, we will suppose that $w_{1}=w_{2}=w^{*}$. Then, however, it holds for the solution $\left(q_{1}, q_{2}\right)$ of the system (1) that $q_{1}=q_{2}=q^{*}$.

Now the fact that the determinant is zero, leads to

$$
\left(1-c-3 q^{*}\right)\left(-2-2 w^{*} \frac{1}{8\left(q^{*}\right)^{2}}\right)-q^{*}=0 \Longleftrightarrow-2(1-c)+5 q^{*}-(1-c) w^{*} \frac{1}{4\left(q^{*}\right)^{2}}+3 w^{*} \frac{1}{4 q^{*}}=0,
$$

whereas (1) implies that

$$
1-c-3 q^{*}+w^{*} \frac{1}{4 q^{*}}=0 .
$$

Combination of these two equations gives $14\left(q^{*}\right)^{2}-8 q^{*}(1-c)+(1-c)^{2}=0$, so that

$$
q^{*}=\frac{4+\sqrt{2}}{14}(1-c) \quad \text { and } \quad w^{*}=\frac{10 \sqrt{2}-2}{49}(1-c)^{2}
$$

In order to prove that $\left(w^{*}, w^{*}\right)$ is an equilibrium of the contract game, we show in Appendix $\mathrm{C}$ that

$$
\frac{\partial \pi_{1}}{\partial w_{1}}\left(w_{1}, w^{*}\right) \begin{cases}>0 & \text { if } w_{1}<w^{*} \\ =0 & \text { if } w_{1}=w^{*} \\ <0 & \text { if } w_{1}>w^{*}\end{cases}
$$

In the remainder of this section, we will illustrate this property in a more intuitive way.

If owner 1 maximizes his profits, given the weight $w_{2}$, in fact he maximizes $\pi_{1}=q_{1}(1-c-Q)$ subject to the restriction $1-c-q_{1}-2 q_{2}+w_{2} \frac{q_{1}}{Q^{2}}=0$ (which corresponds to the reaction curve $\mathcal{R}_{2}$ of manager 2). 
Geometrically, this situation can be analyzed by considering the level curves of the profit function $\pi_{1}$. A typical level curve is represented in Figure 3.

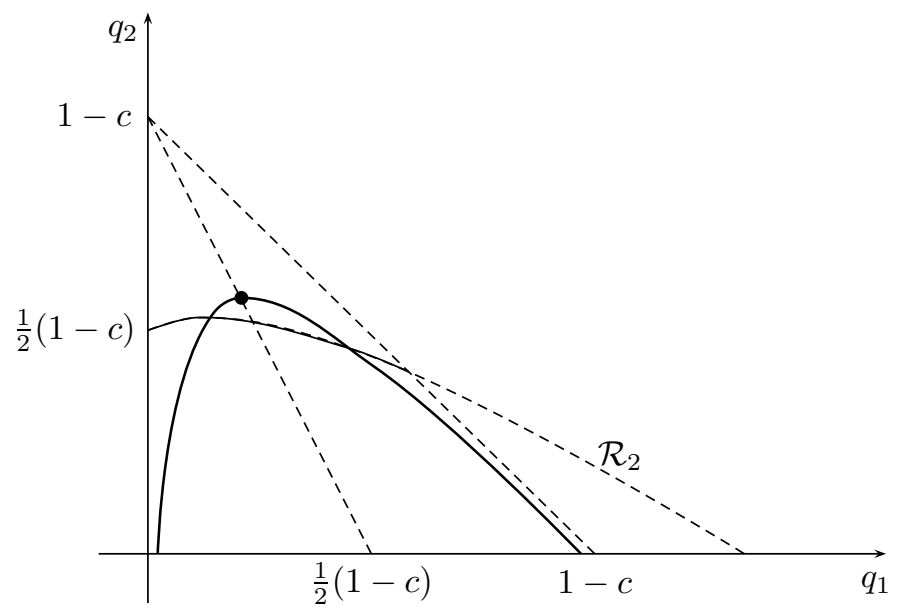

\section{FIGURE 3 A typical iso-profit curve}

Note that each level curve corresponds to a curve with the top lying on manager 1's reaction curve in the classical Cournot situation. Furthermore, the level curves move downwards if the level increases. Obviously, the (unique) best reaction of owner 1 corresponds with the level curve that touches the reaction curve $\mathcal{R}_{2}$ once.

The results obtained in this section are summarized in the following theorem.

THEOREM 2 In the symmetric subgame-perfect equilibrium of the delegation game, the market supply, the profits and the weight are, respectively,

$$
q=\frac{4+\sqrt{2}}{14}(1-c), \quad \pi=\frac{10-\sqrt{2}}{98}(1-c)^{2} \quad \text { and } \quad w=\frac{10 \sqrt{2}-2}{49}(1-c)^{2}
$$

\section{A comparison with other models}

For the sake of convenience, we will refer to the classical Cournot (textbook) case without strategic delegation as the no-delegation case. The delegation models of Vickers (1985), Fershtman (1985), Fershtman and Judd (1987) and Sklivas (1987), which (in essence) all deal with production volume as part of managers' incentive contracts, will be called the sales-delegation cases, whereas this paper's model will be briefly referred to as the market share-delegation case. First, we reflect on a duopoly and compare the outcomes of the market sharedelegation case with the two other cases. We are of opinion that the duopolistic market structure reveals all essential differences between these models. To highlight the differences, we distinguish the composition of incentive contracts, profitability of incumbent rivals, and market supply and social welfare.

Table 1 summarizes all important indicators, concerning the three cases. The results pertaining to the salesdelegation come from Vickers (1985) and are adapted to our normalized model (Vickers uses $p=A-Q$; our model uses $p=1-Q)$. The weights in the contracts, total market supply, profits and social welfare are indicated with $w, Q, \pi$ and $S W$ respectively (concerning all expressions, $c$ equals marginal production costs on a scale from 0 to 1 ). Furthermore, the subscripts $m$ and $s$ refer to the market share-delegation case and the sales-delegation case respectively. 


\begin{tabular}{|c|c|c|c|c|}
\hline \multirow[t]{2}{*}{ model } & \multicolumn{3}{|l|}{ parameter } & \multirow[b]{2}{*}{$S W$} \\
\hline & $w$ & $Q$ & $\pi$ & \\
\hline no-delegation & 0 & $\frac{2}{3}(1-c)$ & $\frac{1}{9}(1-c)^{2}$ & $\frac{4}{9}(1-c)^{2}$ \\
\hline sales-delegation & $\frac{1}{5}(1-c)$ & $\frac{4}{5}(1-c)$ & $\frac{2}{25}(1-c)^{2}$ & $\frac{12}{25}(1-c)^{2}$ \\
\hline market share-delegation & $\approx 0.25(1-c)^{2}$ & $\approx 0.77(1-c)$ & $\approx 0.09(1-c)^{2}$ & $\approx 0.47(1-c)^{2}$ \\
\hline
\end{tabular}

\section{TABLE 1 Essentials of the duopoly case}

Composition of incentive contracts

Each incentive contract is composed of a linear combination of the profit $\pi$ and a non-profit indicator, such as production volume or market share. Therefore, the weights $w$ reveal the owners' emphasis on nonprofitmaximizing managerial behavior in a strategic context. Because the weight attributed to profit is always 1 in our models, the smaller contracts' weights attributed to non-profit indicators are, the more owners direct their managers to pure profit-maximizing behavior. Clearly, the weight decreases w.r.t. increasing marginal $\operatorname{costs} c$, indicating that higher production costs are associated with owners' manipulation towards more pure profit-maximizing behavior. However, the weight $w_{m}$ corresponding to market share-delegation, falls quadratically, whereas the sales-delegation weight $w_{s}$ decreases in a linear way. A graph of both weights as a function of the marginal production costs $c$ is presented in Figure 4. As indicated in the graph with a dotted line, the weight $w_{m}$ only exceeds the weight $w_{s}$ for very efficient production technologies (to be precise: for $\left.0 \leq c<c^{*}=0.193\right)$. For most production processes $\left(c \geq c^{*}\right)$, market share-delegation is associated with smaller weights attributed to market share in the incentive contracts. Hence, we may state that strategic delegation with market share as a managerial incentive leads to more emphasis on profit-maximizing behavior. Note that a case with moderate production efficiency, i.e. $c=0.5$, corresponds with $w_{m}=0.061<w_{s}=$ 0.100. Roughly speaking, in case of sales-delegation 10 percent of the incentive contract consists of production volume, whereas only 6 percent is dedicated to the non-profit managerial indicator in case of market sharedelegation.

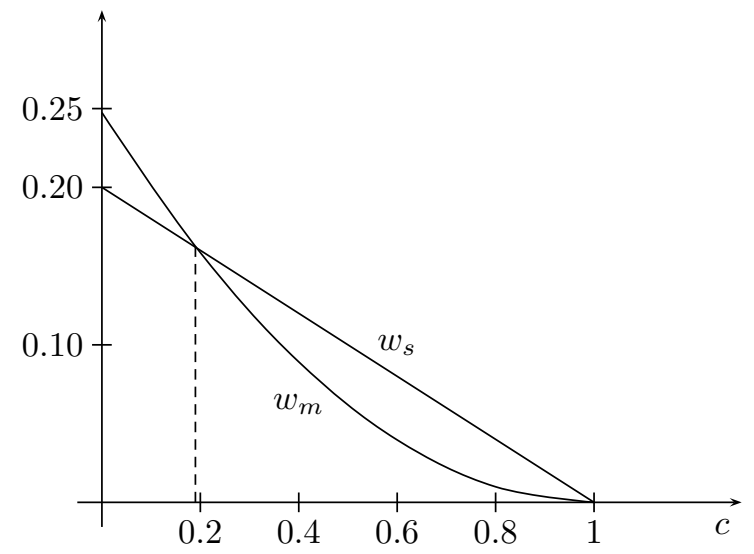

\section{FIGURE 4 Comparison of the composition of incentive contracts in a duopoly}

\section{Profitability of incumbent competitors}

Clearly, similar to the sales-delegation model, the incentive equilibrium of the market share-delegation case corresponds with higher outputs than the classical Cournot-quantity equilibrium. The reason for this in- 
creased output is straightforward: each owner, by using incentives, directs his manager to more aggressive behavior in order to force the competing manager to reduce his/her output. Because each owner acts in the same way at the game's contract stage, a subgame-perfect equilibrium is reached corresponding with positive weights attributed to the manager's performance indicator. Naturally, the increase of market supply in comparison to the no-delegation case leads to lower profits in the incentive equilibrium. However, this paper's analysis reveals that the indicator in the managers' contracts matters. If $\pi_{m}, \pi_{s}$ and $\pi_{n}$ equal profit levels corresponding to the market share-delegation model, the sales-delegation case and the classical no-delegation model, we have (from Table 1):

$$
\pi_{s}=\frac{18}{25} \pi_{n}=0.72 \pi_{n} \quad \text { and } \quad \pi_{m}=\frac{90-9 \sqrt{ } 2}{98} \pi_{n} \approx 0.789 \pi_{n} .
$$

Apparently, the market share-delegation model is associated with to higher equilibrium profits than the sales-delegation case and we have $\pi_{m}=\frac{250-25 \sqrt{ } 2}{196} \pi_{s} \approx 1.095 \pi_{s}$. Reflecting on the contract's composition, we already observed that (in most cases, concerning production efficiency) market share-delegation leads to more emphasis on managerial profit-maximizing behavior. The fact that $\pi_{m}$ is 9.5 percent higher than equilibrium's profitability concerning the sales-delegation model fits in completely.

It is clear that (in a duopoly), if both owners would agree to direct their managers to pure profit-maximizing behavior, their profit would be larger in equilibrium. Fershtman (1985) already reflects on this issue concerning the sales-delegation model and notes that "..giving managers incentives that combine profits and sales maximization may be the dominant strategy for the owners. Thus, even though owners wish to maximize profit, the equilibrium in the market is such that in both firms managerial incentives are combined from profits and sales maximization." In fact, both the market share-delegation and the sales-delegation model deals with a Prisoners' Dilemma at the contract stage of the game, where the only Nash equilibrium corresponds with incentive contracts which are composed of a profit and a nonprofit-maximizing indicator. In his plea for the application of game theory to the issue of trust, van Witteloostuijn (2003) reflects on a Prisoners' Dilemma, arising from a Bertrand duopoly game where incumbent rivals can set low or high prices. In this context, he notes that "untrustworthy behavior emphasizes competitive strategies of aggressive low prices, whilst trustworthy behavior is associated with cooperative strategies of peaceful high-price setting". In fact, our delegation game deals with a competitive strategy. Suppose that both owners would agree on directing their managers to pure profit-maximizing behavior, then such an equilibrium would not be stable in the light of untrustworthy behavior. If one owner would violate the agreement, by giving his manager non-profit incentives, the other owner would face a much lower profit. So the incentive equilibrium is very plausible in a competitive context.

\section{Market supply and social welfare}

Let social welfare $S W$ be defined as the sum of producer and consumer surplus. Then, in terms of our normalized model, it can be expressed as $S W(Q)=\sum_{i=1}^{n} \pi_{i}+0.5 Q^{2}$, where $Q$ equals total market supply with $n$ firms involved. Because $\pi_{i}=q_{i}(1-c-Q)$, we have $S W(Q)=Q\left(1-c-\frac{1}{2} Q\right)$. Clearly, for $Q<1-c$, $S W$ is rising w.r.t. an increasing total market supply $Q$ (social welfare would reach its optimum at $Q=1-c$, corresponding with the case of perfect competition). Because a duopoly leads to (Table 1)

$$
Q_{n}=\frac{2}{3}(1-c)<Q_{m}=\frac{4+\sqrt{ } 2}{7}(1-c)<Q_{s}=\frac{4}{5}(1-c),
$$


we have

$$
S W_{n}=\frac{4}{9}(1-c)^{2}<S W_{m}=\frac{19+3 \sqrt{ } 2}{49}(1-c)^{2}<S W_{s}=\frac{12}{25}(1-c)^{2} .
$$

Total market supply corresponding with the market share-delegation case exceeds total market output concerning the no-delegation case, with $S W_{m}$ is 6.7 percent higher than $S W_{n}$. Because $S W_{s}=1.08 \cdot S W_{n}$, $S W_{m}$ and $S W_{s}$ are almost equal and we have

$$
S W_{m}=\frac{25(19+3 \sqrt{ } 2)}{12 \cdot 49} \approx 0.99 S W_{s} .
$$

Concerning a duopoly, social welfare corresponding to the market share-delegation case is only somewhat lower in comparison to the sales-delegation case. The lower total market supply leads to a lower consumer surplus, but this effect is almost completely compensated by a higher profitability of the incumbent competitors. This result holds in general if an $n$-firm oligopoly is considered.

Results concerning the $n$-firm oligopoly

We highlighted the composition of incentive contracts, profitability of incumbent competitors, and social welfare for the duopolistic market structure. In appendix $\mathrm{D}$, the $n$-firm case is analyzed and (rather complicated) expressions for the weights in the incentive contracts, market supply, profit levels and social welfare are deduced at the incentive equilibrium. Concerning the duopoly case, we stated that the use of market share as a managerial incentive leads to more emphasis on managerial profit-maximizing behavior by the owners, in comparison to the sales-delegation case. Only for very efficient production technologies the opposite holds. Table 2 reveals that this property still stands up if more than two rivals are involved. The weights $w_{s}$ and $w_{m}$ are computed corresponding to (a) a very efficient production technology (marginal production costs are $c=0.1$ on a scale from 0 to 1$)$ and (b) a moderate level of production efficiency $(c=0.5)$. Furthermore, we computed the 'turning point' $c^{*}$; for $c>c^{*}$, the weight $w_{s}$ in the sales incentive contract exceeds the weight

\begin{tabular}{|c|c|c|c|c|c|}
\hline \multirow[t]{2}{*}{$n$} & $c=0.1$ & $c=0.1$ & & $c=0.5$ & $c=0.5$ \\
\hline & $w_{s}$ & $w_{m}$ & $c^{*}$ & $w_{s}$ & $w_{m}$ \\
\hline 2 & 0.180 & 0.201 & 0.193 & 0.100 & 0.062 \\
\hline 3 & 0.180 & 0.201 & 0.194 & 0.100 & 0.062 \\
\hline 4 & 0.159 & 0.173 & 0.174 & 0.088 & 0.053 \\
\hline 5 & 0.138 & 0.147 & 0.153 & 0.077 & 0.045 \\
\hline 6 & 0.122 & 0.126 & 0.135 & 0.068 & 0.039 \\
\hline 7 & 0.108 & 0.110 & 0.120 & 0.060 & 0.034 \\
\hline
\end{tabular}
$w_{m}$ in the market share contract.

TABLE 2 The $n$-firm oligopoly and the composition of contracts

The results of Table 2 speak for themselves. Note that the 'turning point' $c^{*}$ even decreases as the number of firms increases.

Table 3 contains some results concerning profit levels and social welfare for different $n$-firm oligopolies (for $n=2, \cdots, 7)$. Profits and welfare pertaining to the market share-delegation case are, again, compared to the corresponding quantities of the no-delegation and the sales-delegation cases. 


\begin{tabular}{|c|c|c|c|c|}
\hline$n$ & $\frac{\pi_{m}}{\pi_{n}} \times 100 \%$ & $\frac{\pi_{m}}{\pi_{s}} \times 100 \%$ & $\frac{S W_{m}}{S W_{n}} \times 100 \%$ & $\frac{S W_{m}}{S W_{s}} \times 100 \%$ \\
\hline 2 & 78.8 & 109.5 & 106.7 & 98.8 \\
\hline 3 & 52.4 & 109.3 & 105.4 & 99.8 \\
\hline 4 & 37.0 & 106.9 & 103.8 & 99.9 \\
\hline 5 & 28.0 & 105.1 & 102.7 & 100.0 \\
\hline 6 & 22.3 & 103.9 & 102.0 & 100.0 \\
\hline 7 & 18.5 & 103.0 & 101.5 & 100.0 \\
\hline
\end{tabular}

\section{TABLE 3 The $n$-firm oligopoly, profitability and social welfare}

Like in the sales-delegation case, the market share-delegation profits are much lower than the classical Cournot profits and the quotient $\frac{\pi_{m}}{\pi_{n}}$ decreases quickly if the number of incumbent rivals increases (this also introduces a strong incentive for exogenous mergers, as Gonzalez-Maestre and Lopez-Cunat (2001) have pointed out). However, the profit level corresponding to the market share-delegation case always exceeds the sales-delegation profits. Table 3 reveals that this effect is more pronounced if the number of competing firms is smaller.

Similar to the sales-delegation case, market share-delegation is beneficial for social welfare in comparison to the no-delegation case. Strategic delegation triggers a higher total market supply at lower prices and the effect of the increasing consumer surplus amply compensates the decrease of profitability. If we compare social welfare, associated with both delegation cases, it strikes the eye that these quantities are almost equal (only the duopoly case leads to a difference of 1 percent). However, the components, i.e. consumer surplus and producer surplus, do differ. In comparison to the sales-delegation case, market share-delegation results in a higher producer surplus and a lower consumer surplus, indicating that the benefits are shifted from the demand to the supply side.

\section{Conclusion}

Like in the sales-delegation cases, concerning Cournot-quantity competition, we also find that each owner wants to motivate his manager toward higher production levels by offering an incentive contract with some weight attributed to market share. In fact, not surprisingly, each owner directs his manager to more aggressive behavior in order to get competing managers to reduce their market supply. However, we find interesting differences in comparison with the sales-delegation case. Both in the market share-delegation and the salesdelegation cases, a higher-cost production process is associated with more emphasis on pure profit in incentive contracts. But this effect occurs more strongly if market share-delegation is considered. Concerning an $n$-firm oligopoly, and compared to the sales-delegation case, we find that owners put more emphasis on managerial profit-maximizing behavior, indicated by smaller weights attributed to market share in managerial contracts. Exceptions only occur if both firms control very efficient production technologies.

Naturally, more aggressive managerial behavior (directed by firms' owners) leads to higher market supply and higher welfare in comparison with the classical Cournot case. However, total market supply concerning market share-delegation appears to be somewhat more restricted in comparison to the sales-delegation case, 
resulting in a lower consumer surplus. Concerning profits, the market share-delegation case leads to 9.5 percent higher duopoly profits in comparison with the sales-delegation case. We note that the property of higher profitability still holds in case of an $n$-firm oligopoly, although the effect is less pronounced if a larger number of competitors is involved. Interestingly, social welfare corresponding to the market sharedelegation case almost equals welfare concerning the sales-delegation case (only the duopoly case results in a 1 percent difference). Although market share-delegation is associated with a decrease of consumer surplus, profitability is higher in comparison to the sales-delegation case. Consumers' disadvantages are (rather exactly) compensated by producers' extra profitabilities.

Future research can explore delegation games with, for instance, cost asymmetries, motivational differences and Bertrand competition (cf. van Witteloostuijn (1998)). Given the current debate about pros and cons of different renumeration schemes for top managers in the business world, such studies are important to shed light on the competitive and societal consequences of different delegation regimes. 


\section{Appendix}

\section{A Proof of Lemma 1}

LEMMA 1 The second equation of system (1) corresponds, for fixed $w_{2}>0$, to a reaction curve representing the graph of a differentiable, concave function (of $\left.q_{1}\right)$.

PROOF We give the proof for the case with $w_{1} \leq w_{2}$. The other case is similar.

(a) Let $F\left(q_{1}, q_{2}\right)=(1-c)-q_{1}-2 q_{2}+w_{2} \frac{q_{1}}{Q^{2}}$. Since

$$
\frac{\partial F}{\partial q_{2}}\left(q_{1}, q_{2}\right)=-2-2 w_{2} \frac{q_{1}}{Q^{3}}<0
$$

for any $q_{1}$, the function $q_{2} \rightarrow F\left(q_{1}, q_{2}\right)$ is strictly decreasing. Now

$$
F\left(q_{1}, 0\right)=(1-c)-q_{1}+\frac{w_{2}}{q_{1}}
$$

It is straightforward to show that $F\left(q_{1}, 0\right)>0$ for all $0 \leq q_{1}<\frac{1}{2}(1-c)+\sqrt{\frac{1}{4}(1-c)^{2}+w_{2}}$. Furthermore, for any $q_{1}$ satisfying these inequalities, $F\left(q_{1}, q_{2}\right) \downarrow-\infty$ as $q_{2} \rightarrow \infty$. Hence, for any $q_{1}$ satisfying these inequalities, the equation $F\left(q_{1}, q_{2}\right)=0$ has precisely one solution, which will be denoted by $\left(q_{1}, f\left(q_{1}\right)\right)$.

This proves that, for fixed $w_{2}>0$, the second equation of system (1) represents the graph $q_{2}=f\left(q_{1}\right)$ of the function $f$. Note that, using Cardan's method, an explicit expression for $f\left(q_{1}\right)$ can be deduced.

(b) According to the Implicit Function Theorem, the function $f$ is differentiable and

$$
f^{\prime}=\frac{d q_{2}}{d q_{1}}=-\frac{\partial F}{\partial q_{1}} / \frac{\partial F}{\partial q_{2}}=-\frac{1}{2}+\frac{w_{2} q_{2}}{2 Q^{3}+2 w_{2} q_{1}} .
$$

(c) Hence, differentiating once again gives

$$
f^{\prime \prime}=\frac{d^{2} q_{2}}{d q_{1}^{2}}=\frac{\left[2 Q^{3}+2 w_{2} q_{1}\right] w_{2} \frac{d q_{2}}{d q_{1}}-w_{2} q_{2}\left[6 Q^{2}\left(1+\frac{d q_{2}}{d q_{1}}\right)+2 w_{2}\right]}{\left[2 Q^{3}+2 w_{2} q_{1}\right]^{2}}
$$

So

$$
\begin{aligned}
\frac{\left[2 Q^{3}+2 w_{2} q_{1}\right]^{2}}{2 w_{2}} \frac{d^{2} q_{2}}{d q_{1}^{2}} & =\left[Q^{3}+w_{2} q_{1}\right] \frac{d q_{2}}{d q_{1}}-q_{2}\left[3 Q^{2}\left(1+\frac{d q_{2}}{d q_{1}}\right)+w_{2}\right] \\
& =\frac{d q_{2}}{d q_{1}}\left[Q^{2}\left(q_{1}-2 q_{2}\right)+w_{2} q_{1}\right]-3 q_{2} Q^{2}-w_{2} q_{2} .
\end{aligned}
$$

Using the fact that

$$
\frac{d q_{2}}{d q_{1}}=\frac{-Q^{3}+w_{2}\left(q_{2}-q_{1}\right)}{2 Q^{3}+2 w_{2} q_{1}}
$$

leads to

$$
\frac{2\left[Q^{3}+w_{2} q_{1}\right]^{2}}{w_{2}} \frac{d^{2} q_{2}}{d q_{1}^{2}}=\frac{-Q^{3}+w_{2}\left(q_{2}-q_{1}\right)}{2 Q^{3}+2 w_{2} q_{1}}\left[Q^{2}\left(q_{1}-2 q_{2}\right)+w_{2} q_{1}\right]-3 q_{2} Q^{2}-w_{2} q_{2}
$$

or

$$
\frac{4\left[Q^{3}+w_{2} q_{1}\right]^{3}}{w_{2}} \frac{d^{2} q_{2}}{d q_{1}^{2}}=-Q^{5}\left(q_{1}+4 q_{2}\right)-2 w_{2} Q^{3}\left(2 q_{2}+q_{1}\right)-w_{2}^{2} q_{1} Q<0 .
$$

Consequently, $f^{\prime \prime}=\frac{d^{2} q_{2}}{d q_{1}^{2}}<0$.

Hereafter we will determine for the points $\mathrm{A}, \mathrm{B}$ and $\mathrm{C}$ on the reaction curve $\mathcal{R}_{2}$ (see Figure 1 ) the coordinates and the slope of the tangents. 
At the point A, $q_{1}=0$ so that $(1-c)-2 q_{2}=0$. Hence, $q_{2}=\frac{1}{2}(1-c)$. Furthermore,

$$
f^{\prime}(0)=\frac{d q_{2}}{d q_{1}}(0)=-\frac{1}{2}+\frac{w_{2} q_{2}}{2 Q^{3}+2 w_{2} q_{1}}=-\frac{1}{2}+\frac{2 w_{2}}{(1-c)^{2}} .
$$

At the point $\mathrm{B}, q_{1}=q_{2}=q_{B}$ so that

$$
(1-c)-q_{B}-2 q_{B}+w_{2} \frac{q_{B}}{\left(2 q_{B}\right)^{2}}=0 \Longleftrightarrow q_{B}=\frac{1}{6}(1-c)+\frac{1}{6} \sqrt{(1-c)^{2}+3 w_{2}} .
$$

Furthermore,

$$
f^{\prime}\left(q_{B}\right)=\frac{d q_{2}}{d q_{1}}\left(q_{B}\right)=-\frac{1}{2}+\frac{w_{2} q_{2}}{2 Q^{3}+2 w_{2} q_{1}}=-\frac{1}{2+w_{2} / 4 q_{B}^{2}} .
$$

At the point $\mathrm{C}, q_{2}=0$, so that

$$
(1-c)-q_{C}+w_{2} \frac{q_{C}}{q_{C}^{2}}=0 \Longleftrightarrow q_{C}=\frac{1}{2}(1-c)+\frac{1}{2} \sqrt{(1-c)^{2}+4 w_{2}} .
$$

Furthermore,

$$
f^{\prime}\left(q_{C}\right)=\frac{d q_{2}}{d q_{1}}\left(q_{C}\right)=-\frac{1}{2}
$$

$B \quad$ The expression $q_{i}\left(w_{1}, w_{2}\right)$

If $\left(q_{1}\left(w_{1}, w_{2}\right), q_{2}\left(w_{1}, w_{2}\right)\right)$ is the Nash-Cournot equilibrium of the market game corresponding to the pair $\left(w_{1}, w_{2}\right)$, then $q_{1}\left(w_{1}, w_{2}\right)$ and $q_{2}\left(w_{1}, w_{2}\right)$ satisfy the following system:

$$
\left\{\begin{array}{l}
\overbrace{1-2 q_{1}-q_{2}-c+w_{1} \frac{q_{2}}{Q^{2}}}^{=F_{1}\left(q_{1}, q_{2}, w_{1}, w_{2}\right)}=0 \\
\underbrace{1-q_{1}-2 q_{2}-c+w_{2} \frac{q_{1}}{Q^{2}}}_{=F_{2}\left(q_{1}, q_{2}, w_{1}, w_{2}\right)}=0 .
\end{array}\right.
$$

In order to apply the Implicit Function Theorem we determine

$$
\begin{aligned}
& \frac{\partial F_{1}}{\partial q_{1}}=-2-2 w_{1} \frac{q_{2}}{Q^{3}}, \quad \frac{\partial F_{1}}{\partial q_{2}}=-1+w_{1} \frac{q_{1}-q_{2}}{Q^{3}}, \\
& \frac{\partial F_{2}}{\partial q_{1}}=-1+w_{2} \frac{q_{2}-q_{1}}{Q^{3}} \quad \text { and } \quad \frac{\partial F_{2}}{\partial q_{2}}=-2-2 w_{2} \frac{q_{1}}{Q^{3}} .
\end{aligned}
$$

Hence,

$$
J_{F}=\operatorname{det}\left[\begin{array}{ll}
\frac{\partial F_{1}}{\partial q_{1}} & \frac{\partial F_{1}}{\partial q_{2}} \\
\frac{\partial F_{2}}{\partial q_{1}} & \frac{\partial F_{2}}{\partial q_{2}}
\end{array}\right]=3+w_{1} \frac{3 q_{2}+q_{1}}{Q^{3}}+w_{2} \frac{3 q_{1}+q_{2}}{Q^{3}}+\frac{w_{1} w_{2}}{Q^{6}}\left(q_{1}+q_{2}\right)^{2}>0 .
$$

So according to the Implicit Function Theorem, $q_{1}=q_{1}\left(w_{1}, w_{2}\right)$ and $q_{2}=q_{2}\left(w_{1}, w_{2}\right)$, where $q_{1}$ and $q_{2}$ have continuous partial derivatives satisfying

$$
\frac{\partial q_{1}}{\partial w_{1}}=-\frac{1}{J_{F}} \operatorname{det}\left[\begin{array}{ll}
\frac{\partial F_{1}}{\partial w_{1}} & \frac{\partial F_{1}}{\partial q_{2}} \\
\frac{\partial F_{2}}{\partial w_{1}} & \frac{\partial F_{2}}{\partial q_{2}}
\end{array}\right]=-\frac{1}{J_{F}} \operatorname{det}\left[\begin{array}{cc}
\frac{q_{2}}{Q^{2}} & \frac{\partial F_{1}}{\partial q_{2}} \\
0 & \frac{\partial F_{2}}{\partial q_{2}}
\end{array}\right]=-\frac{1}{J_{F}} \frac{q_{2}}{Q^{2}} \cdot\left[-2-2 w_{2} \frac{q_{1}}{Q^{3}}\right]>0 .
$$

and similarly for $\frac{\partial q_{2}}{\partial w_{1}}, \frac{\partial q_{1}}{\partial w_{2}}$ and $\frac{\partial q_{2}}{\partial w_{2}}$. 


\section{A second-order condition for profit maximization}

LEMMA 4 For given $w_{2}$, the function $w_{1} \rightarrow \pi_{1}\left(w_{1}, w_{2}\right)$ has at most one extreme value on the interval $(0, \infty)$.

PROOF In this proof, $w_{2}$ is fixed. Note that choosing $w_{1}$ is equivalent with shifting the dotted curve $\mathcal{R}_{1}$ or moving the intersection $\left(q_{1}\left(w_{1}, w_{2}\right), q_{2}\left(w_{1}, w_{2}\right)\right)$ of the two curves over the curve $\mathcal{R}_{2}$.

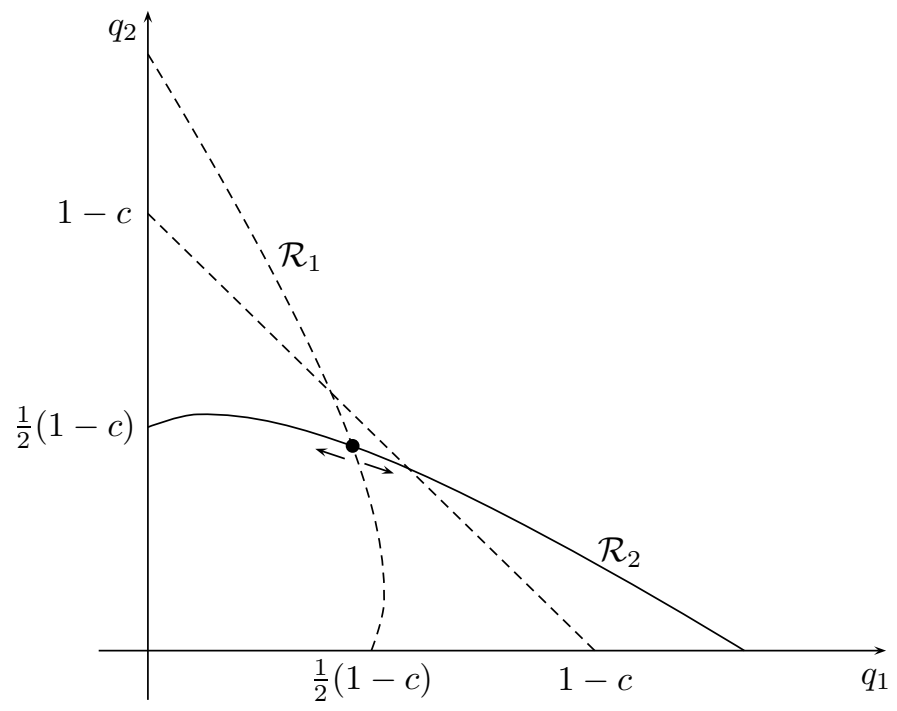

\section{FIGURE 5 Shifting the reaction curve of firm 1}

As a consequence, $q_{2}=f\left(q_{1}\right)$ and

$$
\pi_{1}\left(w_{1}, w_{2}\right)=q_{1}\left(w_{1}, w_{2}\right)\left[(1-c)-q_{1}\left(w_{1}, w_{2}\right)-f\left(q_{1}\left(w_{1}, w_{2}\right)\right)\right],
$$

where $\left(q_{1}, f\left(q_{1}\right)\right)$ is the intersection of the curves $\mathcal{R}_{1}$ and $\mathcal{R}_{2}$. Hence,

$$
\frac{\partial \pi_{1}}{\partial w_{1}}=\frac{\partial q_{1}}{\partial w_{1}}[\underbrace{(1-c)-2 q_{1}-f\left(q_{1}\right)-q_{1} \cdot f^{\prime}\left(q_{1}\right)}_{=H\left(w_{1}, w_{2}\right)}] .
$$

Since $\frac{\partial q_{1}}{\partial w_{1}}>0$, it is sufficient to prove that $H\left(w_{1}, w_{2}\right)$ has at most one zero (note that $w_{2}$ is fixed).

Observe that we are dealing with the expression

$$
H\left(w_{1}, w_{2}\right)=(1-c)-2 q_{1}\left(w_{1}, w_{2}\right)-f\left(q_{1}\left(w_{1}, w_{2}\right)\right)-q_{1}\left(w_{1}, w_{2}\right) \cdot f^{\prime}\left(q_{1}\left(w_{1}, w_{2}\right)\right) .
$$

Hence,

$$
\frac{\partial H}{\partial w_{1}}=\frac{\partial q_{1}}{\partial w_{1}}[\underbrace{-2-2 f^{\prime}\left(q_{1}\right)-q_{1} f^{\prime \prime}\left(q_{1}\right)}_{=L\left(q_{1}\right)}] .
$$

Since $\frac{\partial q_{1}}{\partial w_{1}}>0$, we will consider

$$
\begin{aligned}
L\left(q_{1}\right) & =-2-2 f^{\prime}\left(q_{1}\right)-q_{1} f^{\prime \prime}\left(q_{1}\right) \\
& =-2+\frac{4 Q^{9}+4 w_{2} Q^{6}\left[3 q_{1}-q_{2}\right]+Q^{5}\left[w_{2} q_{1}\left(q_{1}+4 q_{2}\right)\right]+2 w_{2}^{2} q_{1} Q^{3}\left[7 q_{1}-2 q_{2}\right]+w_{2}^{3} q_{1}^{2}\left[5 q_{1}-3 q_{2}\right]}{4\left[Q^{3}+w_{2} q_{1}\right]^{3}} \\
& <-2+\frac{4 Q^{9}+12 w_{2} q_{1} Q^{6}+4 w_{2} q_{1} Q^{6}+14 w_{2}^{2} q_{1}^{2} Q^{3}+5 w_{2}^{3} q_{1}^{3}}{4\left[Q^{3}+w_{2} q_{1}\right]^{3}} \\
& <-2+\frac{8 Q^{9}+24 w_{2} q_{1} Q^{6}+24 w_{2}^{2} q_{1}^{2} Q^{3}+8 w_{2}^{3} q_{1}^{3}}{4\left[Q^{3}+w_{2} q_{1}\right]^{3}}=-2+\frac{8\left[Q^{3}+w_{2} q_{1}\right]^{3}}{4\left[Q^{3}+w_{2} q_{1}\right]^{3}}=0 .
\end{aligned}
$$


This proves that $\frac{\partial H}{\partial w_{1}}<0$, or $H\left(w_{1}, w_{2}\right)$ strictly decreases as $w_{1}$ increases.

D Market share: the general case

Manager $i$ (knowing all the weights) chooses $q_{i}$ in order to maximize

$$
U_{i}=q_{i}(1-Q-c)+w_{i} \frac{q_{i}}{Q}
$$

If $\left(q_{1}^{*}, \ldots, q_{n}^{*}\right)$ is a Nash-Cournot equilibrium of the corresponding market game, then $q_{1}^{*}, \ldots, q_{n}^{*}$ satisfy the equation

$$
1-2 q_{i}-\sum_{k \neq i} q_{k}-c+w_{i} \frac{Q-q_{i}}{Q^{2}}=0 \Longleftrightarrow 1-q_{i}-Q-c+w_{i} \frac{Q-q_{i}}{Q^{2}}=0
$$

for all $i=1,2, \ldots, n$.

Since owner 1 chooses $w_{1}$ in order to maximize his profit $\pi_{1}$, it follows that

$$
\frac{\partial \pi_{1}}{\partial w_{1}}=0 \Longleftrightarrow \frac{\partial q_{1}}{\partial w_{1}}(1-Q-c)-q_{1} \frac{\partial Q}{\partial w_{1}}=0 .
$$

By implicitly differentiating (3) with respect to $w_{1}$ we obtain for $i=2,3, \ldots, n$

$$
-\frac{\partial q_{i}}{\partial w_{1}}-\frac{\partial Q}{\partial w_{1}}+w_{i} \frac{Q^{2}\left(\frac{\partial Q}{\partial w_{1}}-\frac{\partial q_{i}}{\partial w_{1}}\right)-2\left(Q-q_{i}\right) Q \frac{\partial Q}{\partial w_{1}}}{Q^{4}}=0
$$

or

$$
\frac{\partial q_{i}}{\partial w_{1}}\left(-1-w_{i} \frac{1}{Q^{2}}\right)+\frac{\partial Q}{\partial w_{1}}\left(-1+w_{i} \frac{2 q_{i}-Q}{Q^{3}}\right)=0 .
$$

Since (4) is equivalent with

$$
\frac{\partial q_{1}}{\partial w_{1}}\left(1-Q-q_{1}-c\right)-q_{1} \sum_{k \neq 1} \frac{\partial q_{k}}{\partial w_{1}}=0
$$

the following equality holds

$$
\left[\begin{array}{cccc}
1-Q-q_{1}-c & -q_{1} & \cdots & -q_{1} \\
-1+w_{2} \frac{2 q_{2}-Q}{Q^{3}} & -2-w_{2} \frac{2}{Q^{2}}+2 w_{2} \frac{q_{2}}{Q^{3}} & \cdots & -1+w_{2} \frac{2 q_{2}-Q}{Q^{3}} \\
-1+w_{3} \frac{2 q_{3}-Q}{Q^{3}} & -1+w_{3} \frac{2 q_{3}-Q}{Q^{3}} & \cdots & -1+w_{3} \frac{2 q_{3}-Q}{Q^{3}} \\
\vdots & \vdots & \ddots & \vdots \\
-1+w_{n} \frac{2 q_{n}-Q}{Q^{3}} & -1+w_{n} \frac{2 q_{n}-Q}{Q^{3}} & \ldots & -2-w_{n} \frac{2}{Q^{2}}+2 w_{n} \frac{q_{n}}{Q^{3}}
\end{array}\right]\left[\begin{array}{c}
\frac{\partial q_{1}}{\partial w_{1}} \\
\frac{\partial q_{2}}{\partial w_{1}} \\
\vdots \\
\frac{\partial q_{n}}{\partial w_{1}}
\end{array}\right]=\left[\begin{array}{c}
0 \\
0 \\
\vdots \\
0
\end{array}\right]
$$

So the determinant of the foregoing coefficient matrix is zero.

Using the problem's symmetry we will suppose that $w_{1}=\ldots=w_{n}=w$ and that $q_{1}=\ldots=q_{n}=q$.

Then according to $(3)$

$$
1-(n+1) q-c+w \frac{n q-q}{n^{2} q^{2}}=0 \Longleftrightarrow \frac{w}{n^{2} q}=\frac{(n+1) q+c-1}{n-1} .
$$

Furthermore,

and

$$
\begin{aligned}
-1+w_{i} \frac{2 q_{i}-Q}{Q^{3}} & =\frac{-2 q\left(n^{2}-n-1\right)+c(2-n)+n-2}{n(n-1) q} \\
-2-w_{i} \frac{2}{Q^{2}}+2 w_{i} \frac{q_{i}}{Q^{3}} & =\frac{-2 q(1+2 n)-2(c-1)}{n q} .
\end{aligned}
$$


LEMMA 5 The determinant of the $n \times n$ matrix

$$
\left[\begin{array}{ccccc}
a & b & b & \ldots & b \\
c & d & c & \ldots & c \\
c & c & d & \ldots & c \\
\vdots & \vdots & \vdots & \ddots & \vdots \\
c & c & c & \ldots & d
\end{array}\right]
$$

where $a, b, c, d$ are reals numbers, is equal to

$$
(d-c)^{n-2}[a(d+(n-2) c)-(n-1) b c] .
$$

PROOF Note that

$$
\begin{aligned}
& {\left[\begin{array}{ccccc}
a & b & b & \ldots & b \\
c & d & c & \ldots & c \\
c & c & d & \ldots & c \\
\vdots & \vdots & \vdots & \ddots & \vdots \\
c & c & c & \ldots & d
\end{array}\right]=\left[\begin{array}{ccccc}
a-b & 0 & 0 & \ldots & 0 \\
0 & d-c & 0 & \ldots & 0 \\
0 & 0 & d-c & \ldots & 0 \\
\vdots & \vdots & \vdots & \ddots & \vdots \\
0 & 0 & 0 & \ldots & d-c
\end{array}\right]+\left[\begin{array}{c}
b \\
c \\
c \\
\vdots \\
c
\end{array}\right]\left[\begin{array}{llll}
1 & 1 & \ldots & 1
\end{array}\right]} \\
& =\left[\begin{array}{cccc}
a-b & 0 & \ldots & 0 \\
0 & d-c & \ldots & 0 \\
\vdots & \vdots & \ddots & \vdots \\
0 & 0 & \ldots & d-c
\end{array}\right]\left\{I+\left[\begin{array}{cccc}
a-b & 0 & \ldots & 0 \\
0 & d-c & \ldots & 0 \\
\vdots & \vdots & \ddots & \vdots \\
0 & 0 & \ldots & d-c
\end{array}\right]^{-1}\left[\begin{array}{c}
b \\
c \\
\vdots \\
c
\end{array}\right][1 \cdots 1\}\right\} \\
& =\left[\begin{array}{cccc}
a-b & 0 & \ldots & 0 \\
0 & d-c & \ldots & 0 \\
\vdots & \vdots & \ddots & \vdots \\
0 & 0 & \ldots & d-c
\end{array}\right]\left\{I+\left[\begin{array}{c}
\frac{b}{a-b} \\
\frac{c}{d-c} \\
\vdots \\
\frac{1}{d-c}
\end{array}\right]\left[\begin{array}{lll}
1 & \cdots & 1
\end{array}\right]\right\}
\end{aligned}
$$

According to Lemma 3.1 in Szidarovszky and Yen (1995), the determinant of the matrix between curly brackets is equal to

$$
1+\left[\begin{array}{lll}
1 & \cdots & 1
\end{array}\right]\left[\begin{array}{c}
\frac{b}{a-b} \\
\frac{c}{d-c} \\
\vdots \\
\frac{1}{d-c}
\end{array}\right]=1+\frac{b}{a-b}+(n-1) \frac{c}{d-c}
$$

Hence, the determinant in the Lemma is equal to

$$
(a-b)(d-c)^{n-1}\left[1+\frac{b}{a-b}+(n-1) \frac{c}{d-c}\right]=(d-c)^{n-2}[a(d+(n-2) c)-(n-1) b c] .
$$

In our situation

$$
\begin{array}{ll}
a=1-c-(n+1) q & b=-q \\
c=\frac{-2 q\left(n^{2}-n-1\right)+c(2-n)+n-2}{n(n-1) q} & d=\frac{-2 q(1+2 n)-2(c-1)}{n q} .
\end{array}
$$

We investigate two cases. 
If $c=d$, then

$$
\frac{-2 q\left(n^{2}-n-1\right)+c(2-n)+n-2}{n-1}=-2 q(1+2 n)-2(c-1) \Longleftrightarrow q=\frac{1}{2 n}(1-c) .
$$

This output would lead to a negative weight and therefore is irrelevant.

Case II If $a(d+(n-2) c)-(n-1) b c=0$, then

$$
\begin{gathered}
{[1-(n+1) q-c]\left[-2 q(1+2 n)-2(c-1)+(n-2) \frac{-2 q\left(n^{2}-n-1\right)+c(2-n)+n-2}{n-1}\right]} \\
+(n-1) q \frac{-2 q\left(n^{2}-n-1\right)+c(2-n)+n-2}{n-1}=0 \Longleftrightarrow \\
{[1-(n+1) q-c]\left[-2 q\left(n^{3}-n^{2}+1\right)+2(1-c)(n-1)+(1-c)(n-2)^{2}\right]} \\
-2 q^{2}\left(n^{3}-2 n^{2}+1\right)+(n-1)(n-2)(1-c) q=0 .
\end{gathered}
$$

This equation is a quadratic equation in $q$ : it has the form $A q^{2}+B q+C=0$, where

and

$$
\begin{aligned}
& A=2 n^{4}-2 n^{3}+2 n^{2}+2 n, \\
& B=(1-c)\left[-3 n^{3}+4 n^{2}-3 n-2\right], \\
& C=(1-c)^{2}\left(n^{2}-2 n+2\right) .
\end{aligned}
$$

Note that

$$
B^{2}-4 A C=(n-1)^{2}\left(n^{4}+2 n^{3}-3 n^{2}+4 n+4\right)>0 .
$$

Hence,

$$
q=(1-c) \frac{3 n^{3}-4 n^{2}+3 n+2+(n-1) \sqrt{n^{4}+2 n^{3}-3 n^{2}+4 n+4}}{4 n\left(n^{3}-n^{2}+n+1\right)} .
$$

The profit for each firm equals

$$
\pi=q(1-n q-c)=(1-c)^{2} \frac{n^{5}-2 n^{4}+6 n^{3}-4 n^{2}+n+6-(n-1)^{3} \sqrt{n^{4}+2 n^{3}-3 n^{2}+4 n+4}}{8\left(n^{3}-n^{2}+n+1\right)^{2}} .
$$

Using

$$
\frac{w}{n^{2} q}=\frac{(n+1) q+c-1}{n-1}
$$

one can compute the weight, attributed to market share, in the incentive contracts:

$$
\begin{aligned}
& w=(1-c)^{2}\left[\frac{-n^{7}+7 n^{6}-18 n^{5}+18 n^{4}-n^{3}-13 n^{2}+4 n+4}{8(n-1)\left(n^{3}-n^{2}+n+1\right)^{2}}\right. \\
&\left.\quad+\frac{\left(n^{5}-4 n^{3}+6 n^{2}-n-2\right) \sqrt{n^{4}+2 n^{3}-3 n^{2}+4 n+4}}{8(n-1)\left(n^{3}-n^{2}+n+1\right)^{2}}\right] .
\end{aligned}
$$

For social welfare we obtain, using the expressions for $\pi$ and $q$,

$$
\begin{aligned}
S W=(1-c)^{2}\left[\frac{7 n^{6}-16 n^{5}+26 n^{4}-8 n^{3}-5 n^{2}+16 n+4}{16\left(n^{3}-n^{2}+n+1\right)^{2}}\right. & \\
& \left.+\frac{\left(n^{4}-n^{3}+n^{2}+n-2\right) \sqrt{n^{4}+2 n^{3}-3 n^{2}+4 n+4}}{16\left(n^{3}-n^{2}+n+1\right)^{2}}\right] .
\end{aligned}
$$




\section{References}

Basu, K. 1995. Stackelberg Equilibrium in Oligopoly: An Explanation Based on Managerial Incentives. Economic Letters 49, $459-464$.

Baumol, W. 1958. On the Theory of Oligopoly. Economica 25, $187-198$.

Fernández, O., Baixauli, M., Samuel, J. 2003. Motives for Partial Acquisitions between Firms in the Spanish Stock Market. European Journal of Finance 9, 581 - 602.

Fershtman, C. 1985. Managerial Incentives as a Strategic Variable in Duopolistic Environment. International Journal of Industrial Organization 3, $245-253$.

Fershtman, C., Judd, K.L. 1987. Equilibrium Incentives in Oligopoly. American Economic Review 77, 927 $-940$.

González-Maestre, M., López-Cuñat, J. 2001. Delegation and Mergers in Oligopoly. International Journal of Industrial Organization 19, 1263 - 1279.

Güth, W., Kliemt, H., Ockenfels, A. 2003. Fairness versus Efficiency: An Experimental Study of (Mutual) Gift Giving. Journal of Economic Behavior \& Organization 50, 465 - 475.

Hall, M. 1967. Sales Revenue Maximization: An Empirical Examination. Journal of Industrial Economics $15,143-154$

Jensen, M.C., Murphy, K.J. 1990. Performance Pay and Top Management Incentives. Journal of Political Economy 98, $225-264$.

Lackman, C.L., Craycroft J.L. 1974. Sales Maximization and Oligopoly: A Case Study. Journal of Industrial Economics 23, $81-95$.

Lambert, R.A., Larcker, D.F., Weigelt, K. 1991. How Sensitive is Executive Compensation to Organizational Size. Strategic Management Journal 12, 395 - 402.

Lier, A.J. van. 2003. Behavioral Cournot Competition. Ph.D. Thesis. University of Groningen. The Netherlands.

Peck, M.J. 1988. The Large Japanese Corporation. In Meyer, J.R., Gustafson, J.M. (eds), The U.S. Business Corporation: An Institution in Transition. Cambridge MA: Ballinger, 35 - 36.

Rauscher, M. 1992. Keeping up with the Joneses: Chaotic Patterns in a Status Game. Economic Letters $40,287-290$.

Sklivas, S.D. 1987. The Strategic Choice of Managerial Incentives. RAND Journal of Economics 18, $452-$ 458.

Szidarovszky, F., Yen, J. 1995. Dynamic Cournot Oligopolies with Production Adjustment Costs. Journal of Mathematical Economics 24, 95-101.

Szymanski, S. 1994. Strategic Delegation with Endogenous Costs: Duopoly with Wage Bargaining. International Journal of Industrial Organization 12, 105 - 116.

Vickers, J. 1985. Delegation and the Theory of the Firm. Economic Journal 95, 138 - 147.

Witteloostuijn, A. van. 1998. Bridging Behavior and Economic Theories of Decline: Organizational Inertia, Strategic Competition, and Chronic Failure. Management Science 44, 501 - 519.

Witteloostuijn, A. van. 2003. A Game-Theoretic Framework of Trust. International Studies of Management and Organization 33, $53-71$. 
Ziss, S. 2001. Horizontal Mergers and Delegation. International Journal of Industrial Organization 19, $471-492$. 